\title{
Thoughts on the Conversion of New and Old Kinetic Energy
}

\author{
Wen Wei, Li Haowei, Yi Fang \\ Marxism College(Mao Zedong College) \\ Xiangtan University \\ Xiangtan, Hunan, China, 411105
}

\begin{abstract}
Accelerating the transformation of new and old kinetic energy is an inevitable choice to realize the high-quality development of our economy in the new era and also a key move to push forward the structural reform on the supply side and build a socialist modernization power. In the new era, we should adhere to the new concept of development to improve the total factor productivity, the quality of real economic supply, the level of ecological civilization and the orderly transformation and continuation of industries, optimize the government service environment, construct the safeguard mechanism of kinetic energy conversion, adjust the economic structure, upgrade the factors of production, improve the old industries, cultivate new indus tries, vigorously develop the real economy, implement green development, and ensure the orderly transformation of new and old kine tic energy.
\end{abstract}

Keywords-new era; new kinetic energy; new and old kinetic energy conversion; economic high quality development

The report of the Nineteenth National Congress of the CPC pointed out that China's economy has changed from the stage of high-speed growth to the stage of high-quality development, and is in the key period of transforming the mode of development, optimizing the economic structure and transforming the driving force of growth.[1] Speeding up the transformation of new and old energy is the key to cross this threshold. General Secretary Xi Jinping stressed that if China does not take the road of innovation-driven development, the new and old momentum can not be smoothly converted, and it will not be truly strong. Therefore, we must first understand profoundly the importance of accelerating the transformation of new and old kinetic energy.

\section{DEEPLY UNDERSTAND THE SigNIFICANCE OF} ACCElERAting the TRANSFORMATION OF Old AND New KINETIC ENERGY

\section{A. First of all, the implementation of the new development} concept must accelerate the transformation of old and new kinetic energy.

The Fifth Plenary Session of the Eighteenth Central Committee put forward the new development concept of "innovation, coordination, green, opening up and sharing". To implement the new development concept, we must cultivate new momentum. The new kinetic energy is a concept relative to the old kinetic energy. Old kinetic energy is supported by resources, driven by investment and at the cost of sacrificing the environment. It is characterized by high cost, high energy consumption, high pollution, low efficiency and low quality, such as excess and backward capacity. The new kinetic energy is supported by knowledge, technology, information, data, etc., focusing on new technologies, new industries, new formats, new models, and promoting the kinetic energy of industrial intelligence, smart industrialization, cross-border integration, and brand high-end. The conversion of new and old kinetic energy is to transform and upgrade old production capacity, eliminate backward production capacity, and cultivate new production capacity. In the past, the rapid growth of China's economy was mainly driven by unsustainable old kinetic energy. The new development concept puts forward that the cultivation of new kinetic energy is to solve the problem of insufficient old kinetic energy, so the new kinetic energy must reflect the requirements of the new development concept.

\section{B. Second, to achieve high-qualityeconomic development in} China, we must accelerate the transformation of old and new kinetic energy.

Economic high-quality development refers to a country or region's total economic growth, economic structure optimization, economic efficiency enhancement, sustainable economic development and sharing of economic development results. The high quality development of China's economy is characterized by innovation as the endogenous driving force, coordination as the fundamental feature, green as the basic form, opening up as the only way and sharing as the fundamental purpose.[2] After 40 years of reform and opening up, China's economic construction has made tremendous achievements, and its economic scale ranks second in the world. However, the quality construction of China's economic development is relatively backward, the effective supply is seriously inadequate, and the key core technology has long been subject to human.[3] To change this situation and better meet the people's growing needs for a better life, we must achieve high-quality economic development. Old kinetic energy has played an important role in the rapid development of China's economy, but it is difficult to assume the responsibility of achieving high-quality economic development in the new era. Therefore, we must speed up the transformation of new and old kinetic energy. 
C. Thirdly, to promote the structural reform of supply side, we must speed up the transformation of new and old energy.

Supply side structural reform is an important measure to solve the major structural imbalance of China's economy. The report of the Nineteenth National Congress of the Communist Party of China clearly states that we should speed up the development of advanced manufacturing industry, promote the deep integration of Internet, big data, artificial intelligence and real economy, cultivate new growth points and form new momentum in the fields of high-end consumption, innovation leading, green low-carbon, shared economy, modern supply chain, human capital services and so on. [1] From the supply side, new momentum comes not only from new industries, new products, new formats, new models, but also from the optimization and upgrading of traditional industries. At present, the key point of supply-side structural reform is to cultivate new momentum, enhance the quality of the whole supply system and improve the adaptability of supply structure to demand structure while eliminating ineffective supply. Speeding up the transformation of new and old kinetic energy has become an important strategic move to push forward the structural reform of supply side.

\section{Fourth, to build modern industrial system, we must speed} up the transformation of new and old energy.

The report of the Nineteenth National Congress of the Communist Party of China put forward that in order to achieve high-quality economic development in China, we must adhere to the principle of quality first and give priority to efficiency, and strive to speed up the construction of an industrial system featuring the coordinated development of real economy, scientific and technological innovation, modern finance and human resources.[1] The modern industrial system is an important part of the modern economic system, with real economy as the main body, science and technology innovation as the driving force, modern finance as the blood, and human capital as the most valuable resources. Whether we can successfully build a modern economic system directly depends on whether we can successfully build a modern industrial system. From the perspective of industry, the transformation of new and old energy is mainly reflected in the replacement of old industries by new industries, that is, through the transformation of new and old kinetic energy, the old industries will be upgraded, new industries will be fostered, and the industrial system of coordinated development of real economy, scientific and technological innovation, modern finance and human resources will be accelerated and the vigorous development of new technologies, new industries and new formats will be promoted, providing effective support for the transformation and upgrading of economic structure.

\section{E. Fifth, to enter the ranks of high-income countries, we must cultivate new momentum.}

After 40 years of reform and opening up, China has become a middle-income country and is moving towards a high-income country, but achieving this leap is no easy task. After World War II, although more than 110 economies have entered the middle-income stage, only 13 economies have entered the high-income ranks. The main reasons for not realizing the leap are political turmoil, domestic economic development strategy mistakes, financial crisis, economic crisis and so on. Successful leapfrogging economies are due to the realization of new and old kinetic energy conversion in different stages of development and the continuation of high-quality economic development. China is now in a critical period of crossing the "middle-income trap". Economic development is facing a series of problems, such as rising labor prices, decreasing investment efficiency and hindering exports. Therefore, if we want to enter the high income stage smoothly, we must cultivate new kinetic energy.

\section{Firmly Grasp the Main Direction of SPEEDING UP THE CONVERSION OF OLD AND NEW KINETIC ENERGY}

\section{A. Optimize resource allocation and increase total factor productivity.}

Total Factor Productivity (TFP) is an index used to measure production efficiency. It refers to the increase of output caused by technological progress and capacity realization besides the input of each factor, is the residual income after eliminating the contribution of input factors and was first put forward by Solow (1957), so it is also called Solow residual. It calculates the "surplus value" after eliminating labor, capital, land and other factors, and to a great extent determines the quality of economic growth. The main driving force of China's economic growth in the past 40 years of reform and opening up is the "demographic dividend effect" brought about by a large number of cheap labor, but the demographic dividend is gradually disappearing. The second is the rapid growth of investment effect, but the growth rate of investment in most provinces and cities has slowed down. Therefore, it will become more difficult and unsustainable to continue to rely on increasing capital and labor input to promote economic growth in the future. To maintain economic growth, great efforts must be made to improve total factor productivity.

\section{B. Focus on the development of the real economy and improve the quality of the supply system.}

The report of the Nineteenth National Congress pointed out that during the critical period of building a modern economic system, 'the focus of economic development must be put on the real economy, and improving the quality of the supply system should be the main direction of attack".[1] The real economy is the foundation of a strong country and enriching people. Improving the supply quality of the real economy is not only the solution to the problem of 'being unrealistic to being virtual" in China's economic development, but also the key to satisfying the people's needs for a better life. Improving the quality of the supply system is to improve the degree of products to meet the needs of consumer consumption upgrading, the ability of enterprises to adapt to market competition, and the ability of industrial transformation and upgrading to adapt to consumption upgrades.[4] Therefore, the quality of supply system determines the quality of China's economic growth, and then determines the transformation of China's economic development mode and sustainable economic development. Therefore, efforts to improve the 
supply quality of the real economy have become a key task and an important measure to speed up the conversion of new and old kinetic energy.

\section{Realize the orderly connection of the industry and maintain sustained economic development.}

Since the reform and opening up, China's economy has been developing at a high speed, and the economic structure has been optimized and upgraded. The three industrial structures have changed from the "two-three-one" structure to the "three-two-one" structure, and the trend of high-quality development has gradually emerged. For example, in the first half of this year, the added value of first, second, third industries in Hunan increased by $3.2 \%, 6.7 \%$ and $9.7 \%$, respectively; [5]The internal structure of many industries has also undergone qualitative changes. For example, Hualing Group has become the first state-owned enterprise in Hunan Province to break through 100 billion Yuan in sales revenue in 2017 by upgrading product levels, optimizing enterprise structure and enhancing development stamina. However, the external environment of China's economic development is still complex, the problem of insufficient internal development imbalance still exists, and the deep-seated structural contradictions that restrict the sustained and rapid development of our economy remain to be resolved. Therefore, it is necessary to speed up the transformation of old and new kinetic energy, improve the level of industrial development, achieve orderly industrial continuity, and maintain sustainable economic development.

\section{Implement green development and build an ecological civilization.}

Since the 18th National Congress of the CPC, the CPC Central Committee, with Xi Jinping as its core, has attached great importance to the construction of ecological civilization and the protection of ecological environment. Remarkable achievements have been made in building ecological civilization. China has become an important participant, contributor and leader in the construction of global ecological civilization. However, there are still many deficiencies in the construction of ecological civilization and the protection of ecological environment in China. For example, some units do not have enough understanding of the importance of ecological environment protection, and their responsibilities can not be implemented in place. The contradiction between economic and social development and the protection of ecological environment is still outstanding. New and old environmental problems are intertwined in urban and rural areas, and regional, layout and structural environmental risks are highlighted. Severe pollution weather, black and stinky water, garbage siege, ecological destruction and other problems occur from time to time. To change this situation, we must implement the green development of "low consumption, low emission, low pollution and high benefit". Therefore, the implementation of green development and the overall improvement of the level of ecological civilization will be an important part of accelerating the transformation of new and old kinetic energy in China.
III. Thoughts ON SPEEDING UP THE CONVERSiON OF NeW AND OLD KINETIC ENERGY

\section{A. The first is to optimize the government management service environment.}

Governments at all levels should take the initiative to meet the needs of accelerating the growth of new kinetic energy and upgrading the transformation of traditional kinetic energy, formulate effective strategies for the development and expansion of new kinetic energy, plan innovative development of new industries, deepen the reform of the "release uniform" system, increase the reform of the examination and approval system, simplify the examination and approval before the event, strengthen the supervision after the event, further improve the efficiency of administrative examination and approval services, optimize the business environment, implement information management and online approval and deadline closure system, improve business efficiency, speed up the dynamic adjustment of laws and policies and standards, and improve the efficiency of entrepreneurial innovation service.

\section{B. The second is to strengthen the supply of effective institutions.}

Effective institutional supply is an important guarantee for the transformation of new and old kinetic energy. Almost all the industrial strategic adjustments and transformations in Japan and South Korea have been made and promoted by the government. Therefore, first, we must build an overall and coordinated organizational support to ensure the rational allocation of new and old kinetic energy resources. Secondly, we should establish a policy system and institutional environment to encourage attempts, dare to make mistakes and tolerate failures, so as to fully stimulate the initiative of market participants in innovation and entrepreneurship. Third, we should give full play to the role of the market mechanism and make the enterprise the main body of the kinetic energy conversion. Fourth, we should improve the social capital investment mechanism and rationally guide social capital to participate in economic construction. Fifth, we should innovate the performance appraisal mechanism and appropriately increase the weight of the system reform assessment that is conducive to economic growth. Sixth, we should innovate fiscal and tax policies and industrial policies to provide specific policy support for the transformation of new and old energy.

\section{The third is to optimize the economic structure.}

Firstly, we should vigorously adjust the industrial structure to form a new pattern dominated by science and technology, productive and life-oriented services, accelerate the development of science and technology services, such as research and development design, develop and expand producer services, such as third-party logistics, and focus on the development of life-related services, such as health care. Second, we should speed up the integration of urban and rural areas, including land management system reform, household registration system reform, strengthen urban and rural infrastructure and public service facilities, improve the level of basic public services in rural areas, and gradually realize the integration of urban and rural development. Thirdly, we should 
accelerate the pace of regional integration, strengthen the crossregional flow of capital, labor and other factors, and form a multi-center, networked regional cooperative development pattern.

\section{The fourth is to upgrade production factors.}

To speed up the transformation of new and old kinetic energy and to cultivate new kinetic energy need new factors of production support. First, we should strengthen independent innovation, achieve breakthroughs in $R \& D$ and industrial application of key core technologies, enhance the core competence of traditional industries, vigorously develop new industries, and realize industrial wisdom and industrialization of wisdom by jointly tackling key problems, introducing and absorbing innovations, and integrating innovations. Second, we should make full use of information technology such as the Internet of Things and the Internet of Things to create new business forms and create new economic growth points. Third, efforts should be made to cultivate high-quality workers with craftsmanship in mastering new technologies, and to increase investment in medical, health, social security and other social infrastructure areas to lay a good foundation for improving the quality of human capital. Fourth, we should promote the rational flow and effective accumulation of knowledge, technology, information and data, improve the flow mechanism of intellectual elements and the open and sharing system of data resources, strengthen the application mechanism for accelerating the transformation of scientific and technological achievements, and innovate new technologies and new formats to upgrade traditional industries.

\section{E. The fifth is to upgrade the old industry and cultivate new industries.}

First, we should transform and upgrade the traditional industries, which can not only eliminate backward excess capacity, but also upgrade the traditional superior industries, extend the industrial chain, upgrade the value chain, integrate the technical chain and promote the "three-chain integration" and the high-quality and efficient development of the industry.[6] Second, we should develop strategic emerging industries, plan a new generation of information technology, biology, high-end equipment and other heavyweight future industries, build an important strategic emerging industry policy source and agglomeration area and build and cultivate innovative emerging industrial clusters with international competitiveness. Third, we should actively cultivate new formats and new models, and accelerate the cultivation of new products, new models and new formats based on the Internet and artificial intelligence. Fourthly, we should promote green development, focus on promoting regional pattern functionalization, low-carbon industrial development, efficient utilization of resources, and institutionalization of green development.

\section{F. The sixth is to share the results of the conversion of old and new kinetic energy with the people as the center.}

The essence of speeding up the transformation of new and old kinetic energy is to promote the high-quality development of the economy, so as to improve the people's sense of acquisition and happiness. Therefore, we should implement the new concept of "people centred" and share the fruits of new and old energy conversion. First, we should formulate and implement the national income growth plan, constantly narrow the income gap, prevent unfair income distribution, polarization between the rich and the poor and fall into the "middle income trap". Second, we should develop health care, social security, cultural and sports, tourism and leisure and other well-being industries, make up for the shortcomings of social security and livelihood benefits, and improve people's well-being. Third, we should increase the construction of urban and rural infrastructure and public service facilities and make up for the shortcomings of convenient travel, life and comfort,[6] to basically realize the equalization of urban and rural public services.

In short, the conversion of new and old kinetic energy is both a practical problem and a theoretical one. To solve this problem, we must fully implement the spirit of the Nineteenth National Congress of the Communist Party of China and the document spirit of the State Council on accelerating the successive conversion of new and old kinetic energy, innovate management and optimize service, transform and upgrade old kinetic energy, cultivate and strengthen new kinetic energy, speed up the transformation of new and old kinetic energy, and promote high-quality economic development.

\section{REFERENCES}

[1] Xi Jinping. Win the Battle to Build A Well-off Society in An All-round Way and the Great Victory of Socialism with Chinese Characteristics in the New Era. People's Daily. October 28, 201701 edition.

[2] Zhou Xiaomao, etc. High-quality Economic Development and Its Institutional Environment, "New Power, New Kinetic Energy and Hunan High-quality Development" Excellent Papers. September 2018, 23 pages.

[3] Chen He. Deepen Supply-side Structural Reform. The Party's 19th National Congress Report Tutorial. People's Publishing House. October 2017, 189.

[4] Huang Qunhui. Focus on Improving the Quality of the Supply of the Real Economy. Guangming Daily. February 07, 2017, 11 edition.

[5] Li Yannan. The News Briefing on the Economic Situation of Hunan in the First Half of 2018. Released on July 18, 2018.

[6] See Liu Bing. Accurately Grasp the Key Tasks and Important Measures of the Conversion of Old and New Kinetic Energy. Theoretical Study. No. 8 of 2017. 